\title{
PengembanganTrainer Osilator Analog berbasis IC Op-Amp (Studi Kasus Penelitian R\&D di JTE FT UM)
}

\author{
Syifaul Fuada*1, Hakkun Elmunsyah ${ }^{2}$, Suwasono ${ }^{3}$ \\ *1 University Center of Excellence on Microelectronics, Institut Teknologi Bandung (ITB) \\ 2,3 Jurusan Teknik Elektro, Fakultas Teknik, Universitas Negeri Malang \\ syifaulfuada@pme.itb.ac.id
}

\begin{abstract}
Makalah ini merupakan penelitian pengembangan (R\&D) yang menghasilkan seperangkat produk media pembelajaran praktikum sistem instrumentasi analog, yaitu pembangkit sinyal (osilator) yang terdiri dari atas produk yakni: (1) alat peraga atautrainer yang terdiri atas osilator Phase Shift RC; osilator Wien Bridge; osilator Hartley; osilator Colpitts; dan Astable Multivibrator. (2) Modul praktikum pegangan dosen dan modul praktikum untuk mahasiswa, serta (3) Manual Bookyang merupakan petunjuk penggunaan alat peraga. Objek peneltian dilakukan di Jurusan Teknik Elektro, Fakultas Teknik, Universitas Negeri Malang (JTE FT UM) yang dilatarbelakangi oleh perlunya alat peraga osilator dilabolatoriumnya untuk menunjang kelancaran kegiatan pembelajaran. Ketiga produk telah diuji coba baik secara fungsional maupun uji kelayakan pemakaian produk yang dilakukan pada 3 (tiga) kelompok responden yakni: Ahli media, Ahli materi,dan mahasiswa. Hasil penelitian menunjukkan bahwa produk telah memenuhi kriteria valid dari para ahli dan mendapat respon positif dari mahasiswa praktikan. Dengan demikian perangkat media yang dikembangkan sudah layak untuk digunakan dalam pembelajaran praktikum.
\end{abstract}

Kata kunci: Media pembelajaran, Osilator, trainer board

\section{Pendahuluan}

Osilator merupakan salah satu bagian dari sistem elektronika yang berfungsi untuk membangkitkan frekuensi tertentu dalam bentuk sinyalsinusoid, kotak (square), gigi gergaji (sawtooth), atau segitiga.Pada sistem digital, umumnya osilator digunakan sebagai clock atau pembangkit pulsa [1-2]. Sementara di jenjang Perguruan Tinggi, materi tentang osilator memang selalu disajikan kepada mahasiswa tingkat I atau tingkat lanjut pada jurusan ilmu rumpun elektro baik nonkependidikan maupun kependidikan [3-5].

Jurusan Teknik Elekro merupakan bagian dari Fakultas Teknik Universitas Negeri Malang yang mana pada setiap tahun selalu dilakukan upgrade katalog kurikulum guna mendukung pengembangan IPTEK terkini baik dari segi silabus, penyediaan sarana dan prasarana kuliah, dan buku-buku pedoman perkuliahan. Perubahan tersebut berdasarkan tuntutan perkembangan tekonologi, kebutuhan industri, saran para alumnus dan orang tua 
serta dari para stakeholder yang berkepentingan sehingga diharapkan lulusannya memiliki skill yang kompeten.

Mata kuliah instrumentasi industri (kode matkul: PTEL659) dan workshop/praktikum instrumentasi industri (kode matkul: PTEL660) merupakan mata kuliah wajib yang diajarkan pada mahasiswa program S1 [6], sehingga mahasiswa diharuskan untuk menguasai seluruh subbab pada mata kuliah tersebut. Namun pada proses pembelajaran terdapat kesenjangan khususnya pada subbab osilator. Hasil wawancara pada dosen pengampu mata kuliah tersebut menyatakan bahwa kenyataannya, kompetensi yang tercantumdibuku katalogtidak semuanya terlaksana dengan baik karena perangkat media pembelajaran belum tersedia. Selama ini, untuk melaksanakan praktikum osilator mahasiswa terbatas dengan penggunaan project board yaknimenyambung antar komponen menggunakan kabel jumper.Ditemukan kasus seringnya terjadi trouble saat proses praktikum, misalnya sinyal terosilasi tidak muncul karena faktor kerenggangan kabeljumper, kesalahan dalam penyambungan antar komponenatau beberapa faktor teknis lain. Akibatnya efektivitas pelaksanaan praktikum masih minim karena mahasiswa praktikan lebih sering trouble shootingdaripada pengambilan data. Ditambah lagi kemampuan mahasiswa pada suatu kelas praktikum berbeda-beda, terdapat mahasiswa yang cekatan dalam proses jumpering dan ada pula yang kurang cakap sehingga jam praktikum yang tersedia menjadi kurang efisien. Semua penyebab diatas tentu dapat menjadikan tujuan pembelajaran belum tercapai secara maksimal.

Selanjutnya dosen yang bersangkutan menyarankan agar dikembangkan sebuah trainer beserta perangkat ajar yakni modul tercetak dan manual book untuk menunjang pembelajaran pada mata kuliah Workshop Instrumentasi Industri dengan harapan dapat mengurangi permasalahan diatas.Media serupa telah diproduksi diluar negeri, namun mendesain media secara mandiri merupakan langkah efektif dan ekonomis. Karena alat dan bahan telah tersedia dipasaran lokal sehingga lebih terjangkau (low-cost) dalam proses produksinya dibandingkan dengan membeli trainer osilator yang impor dari luar negeri. Kemudian produk penelitian pengembangan telah terverivikasi oleh ahli dilingkungan universitas tersebut, sehingga akan lebih sesuai dengan kompetensi pada silabus perkuliahan dan tujuan pembelajaran, serta lebih menjamin aspek interactivity, robust, portability dan telah mendapat respon positif dari mahasiswa melalui uji coba produk. Berdasarkan permasalahan tersebut maka dilakukan penelitian pengembangan dengan tujuan konkrit untuk merancang, mengimplementasikan rancangan dan melakukan validasitrainer osilator beserta perangkat pelengkap berupa modul ajar tercetak yakni modul praktikum untuk mahasiswa dan pegangan dosen serta manual book atau buku panduan pelaksanaan praktikum.

Menurut Khosnevis dalam [7]trainermerupakan proses simulasi aplikasi membangun model dari sistem nyata atau usulan sistem, melakukan eksperimen dengan model tersebut untuk menjelaskan perilaku sistem, mempelajari kinerja sistem, atau untuk membangun sistem baru sesuai dengan kinerja yang diinginkan.Trainer dapat didefinisikan sebagai media pembelajaran merupakan simulasi proses perancangan model dari suatu sistem yang nyata dilanjutkan dengan pelaksanaan eksperimen terhadap terhadap model untuk mempelajari perilaku dari sistem itu sendiri sehingga proses penyaluran informasi kepada peserta didik dapat terlaksana. Kelebihan penggunaan trainer sebagai media pembelajaran yakni: (a) Simulasi memungkinkan untuk melakukan studi jangka panjang dalam waktu yang relatif singkat; (b) Simulasi dapat mengestimasi kinerja sistem pada kondisi tertentu dan memberikan alternatif desain terbaik sesuai dengan spesifikasi yang diinginkan; (c) Simulasi menjadikan tidak adanya resiko saat melakukan eksperimen; dan (d) Sifatnya konkret dan lebih realistis dalam memunculkan pokok masalah, jika dibandingkan dengan bahasa 
verbal[7].Dapat disimpulkan bahwa Trainer adalah alat bantu dalam suatu proses pembelajaran yang dipergunakan pebelajar untuk memperagakan materi pelajaran sehingga materi pembelajaran lebih cepat diterima peserta didik dengan utuh serta menarik minat peserta didik untuk belajar lebih lanjut.

Sedangkan modul praktikum merupakan bahan belajar untuk peserta didik agar dapat belajar mandiri. Didalamnya memuat buku petunjuk atau prosedur kerja suatu kegiatan praktik yang harus dilakukan peserta didik dalam rangka penguasaan kemampuan psikomotorik. Modul praktikum menurut [8] berisi tentang: (1) halaman sampul; (2) kata pengantar; (3) daftar isi; (4) peta kedudukan modul, dan (5) pendahuluan. pendahuluan berisi tentang: (a) deskripsi; (b) prasyarat; (c) petunjuk penggunaan modul; (d) tujuan; (e) diagram pencapaian kompetensi; (f) kegiatan belajar ke-n; (g) evaluasi; (h) pedoman penilaian; (i) daftar pustaka.kegiatan belajar pada poin "f" tersebut berisi tentang: (1) tujuan; (2) materi; (3) lembar kerja praktek. lembar kerja praktek berisi tentang: (a) alat dan bahan; (b) keselamatan dan kesehatan kerja; (c) langkah kerja; (d) lembar pengamatan (hasil, analisis hasil, kesimpulan).

Hasil penelitian ini merupakan sarana untuk memenuhi kompetensi yang harus dikuasai oleh mahasiswa prodi S1 Pendidikan Teknik Elektro Jurusan Teknik Elektro Fakultas Teknik Universitas Negeri Malang (JTE FT UM).

\section{Metode Penelitian}

Penelitian ini merupakan penelitian R\&D, penulis menggunakan model Sugiyono[9] yang telah disesuaikan dengan objek penelitian. Gambar 1 merupakan tahapan-tahapan penelitian, alasan menggunakan model ini adalah pada bagian uji coba ke praktikan tidak ditentukan berapa jumlah responden, sehingga peneliti dapat menentukan sendiri teknik pemilihan responden. Selain itu langkah-langkah penelitian pada model Sugiyono [9] sangat sistematis mulai dari awal sampai akhir sehingga pelaksanaan penelitian dapat ditempuh dengan efektif dalam jangka waktu yang lebih efisien dengan hasil yang dapat dipertanggungjawabkan secara akademik.

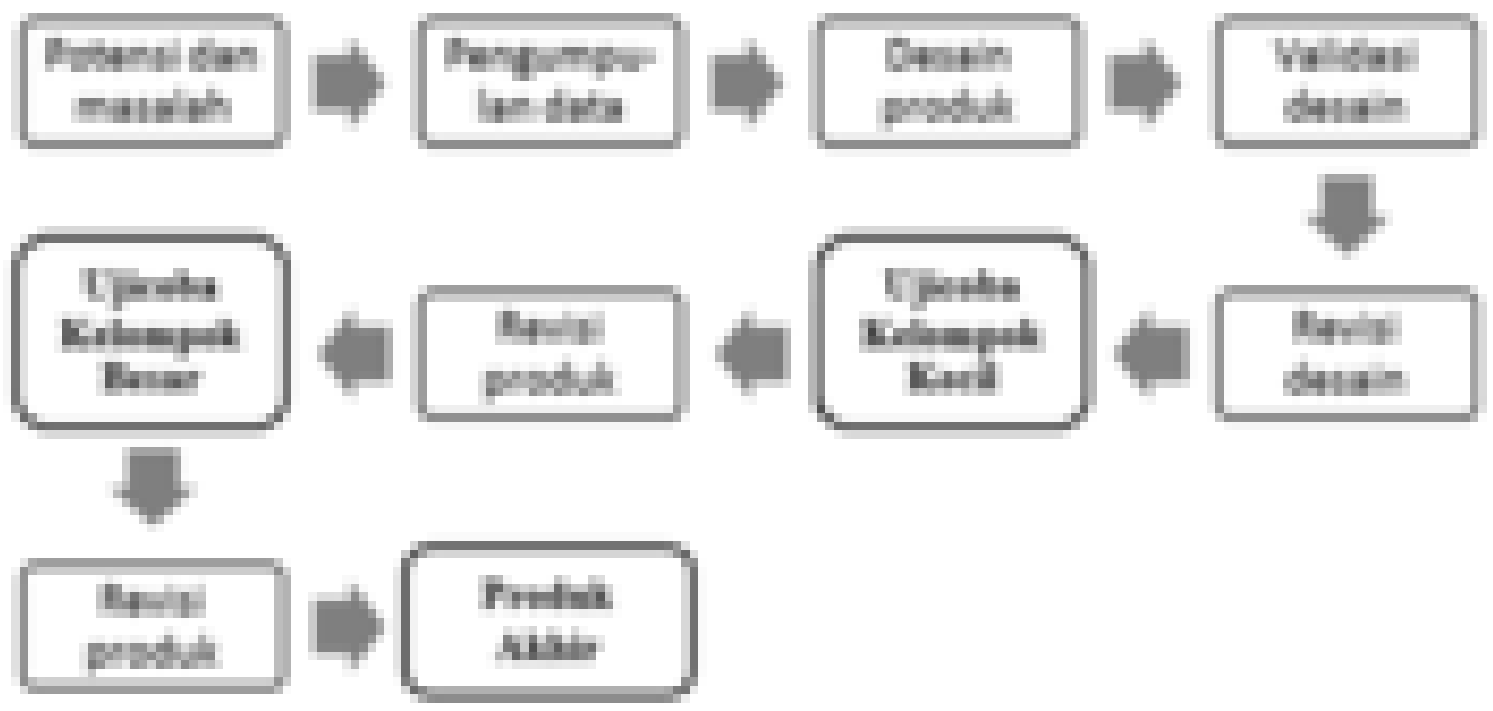

Gambar 1. Tahapan penelitian menurut model Sugiyono 
Tahap mengidentifikasi "potensi dan masalah", pada tahap ini dilakukan observasi kenyataan dilapangan dan wawancara ke dosen pembina mata kuliahWorkshop Instrumentasi Industri di JTE FT UM dan didapatkan kesimpulan bahwa kompetensi yang tertulis pada katalog belum semua terlaksana karena media untuk praktikum sebagian besar belum tersedia khususnya pada subbab pembangkit sinyal (Osilator). Sehingga dibutuhkan suatu media agar mahasiswa dapat mempraktekkan mata kuliah teori dengan cara yang efektif dan waktu yang efisien. Adapun silabus mata kuliahsasaran penelitian pengembangan ditunjukkan pada Tabel I. 
Tabel 1. Silabus mata kuliahWorkshop Instrumentasi Industri di JTE FT UM

\begin{tabular}{|l|l|}
\hline PTEL660 & Workshop Instrumentasi Industri (1 SKS \& 2 JS) \\
\hline Prasyarat: $\quad$ PTEL659 \\
Tujuan: \\
Memberikan keterampilan merancang, merakit dan menguji rangkaian elektronika \\
untuk instrumentasi pada proses produksi \\
Kompetensi: \\
Pokok bahasan yang disajikan meliputi: Rangkaian Penguatan: penguatan \\
diferensial dan penguat instrumentasi; Pembangkit sinyal (Osilator): LC, RC dan \\
Relaksasi; Rangkaian Filter aktif: LPF, HPF, Band Pass Filter; Rangkaian filter \\
digital; konversi sinyal; Rangkaian ADC dan DAC, noise dan reduksi noise); \\
Aplikasi penguatan dan pemrosesan sinyal pada sensor dan tranduser, Instrumentasi \\
pada sistem kontrol.
\end{tabular}

Tahap "pengumpulan data", pada tahap ini literatur-literatur yang berkaitan dengan teori-teori osilator dikumpulkan sebagai bahan pendukung penyusunan modul praktikum. Kemudian mencari rujukan desain untuk pembuatan trainer.

Tahap "desain produk", pada tahap ini rancangan produk trainerdisusun dan disesuaikan dengan materi-materiosilatorpada mata kuliah Workshop Instrumentasi Industri. Gambar 2 merupakan rancangan produk trainer dan modul tambahan/sekunder, yakni resistor, inductor, dan capacitor (RLC).

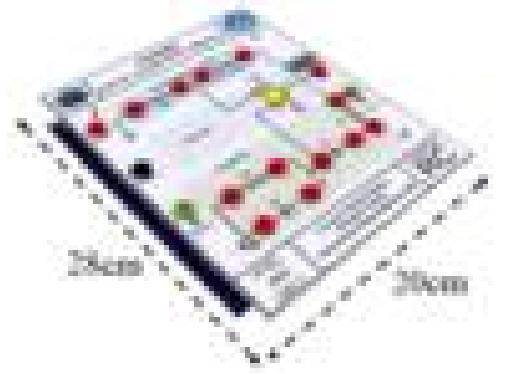

(a)

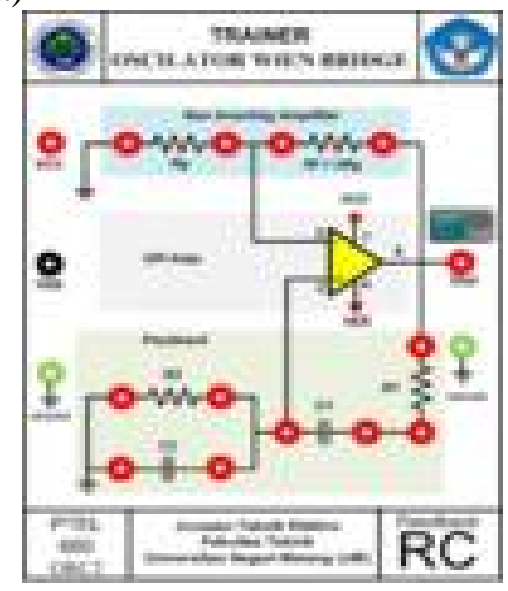

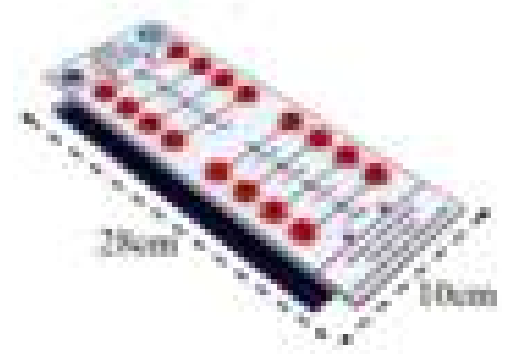

(b)

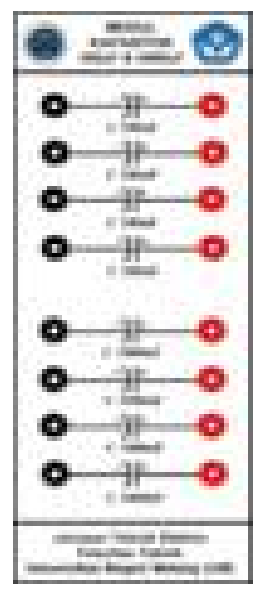


(c)

(d)

Gambar 2. Desain produk R\&D (a) trainer osilator tampak samping; (b) modul capacitor tampak samping (c)tampilan depan trainer osilator (d) modul capacitor tampak depan

Sementara desain modul cetak yang akan disusun mengacu pada silabus mata kuliah dan indikatornya. Tabel 2 merupakan deskripsi modul praktikum untuk mahasiswa dan modul praktikum pegangan dosen. Namun untuk modul praktikum pegangan dosen, pada halaman terakhir ditambahkan kunci jawaban evaluasi dan pedoman penilaian.

Tabel 2. Deskripsi tentang konten pada modul praktikum

\begin{tabular}{|c|c|}
\hline Variabel & Uraian \\
\hline Deskripsi judul & $\begin{array}{l}\text { Berisi tentang nama dan ruang lingkup isi modul, kaitan } \\
\text { modul dengan modul lainnya, kompetensi yang akan } \\
\text { dicapai setelah menyelesaikan modul, dan manfaat } \\
\text { kompetensi tersebut dalam proses pembelajaran. }\end{array}$ \\
\hline Prasyarat & $\begin{array}{l}\text { Berisi tentang kemampuan awal yang dipersyaratkan } \\
\text { untuk mempelajari modul tersebut dan mata kuliah yang } \\
\text { harus ditempuh terlebih dahulu sebelum mempelajari } \\
\text { tentang osilator. }\end{array}$ \\
\hline $\begin{array}{l}\text { Petunjuk penggunaan } \\
\text { modul, }\end{array}$ & $\begin{array}{l}\text { Petunjuk penggunaan modul ajar terdiri dari modul } \\
\text { pegangan dosen sebagai pemelajar dan petunjuk bagi } \\
\text { mahasiswa sebagai pembelajar. Berisi tentang langkah- } \\
\text { langkah belajar menggunakantrainerosilator beserta } \\
\text { perlengkapannya. }\end{array}$ \\
\hline Tujuan pembelajaran & $\begin{array}{l}\text { Berisi tentang tujuan yang ingin dicapai dalam } \\
\text { menyelesaikan modul praktikum osilatorpada mata } \\
\text { kuliah Workshop Instrumentasi Industri. }\end{array}$ \\
\hline Silabus Pembelajaran & $\begin{array}{l}\text { merupakan silabus berdasarkan katalog jurusan teknik } \\
\text { elektro edisi terbaru. }\end{array}$ \\
\hline $\begin{array}{l}\text { Diagram Pencapaian } \\
\text { Kompetensi }\end{array}$ & Berisi tentang kedudukan mata kuliah bentuk diagram. \\
\hline Peta kedudukan modul & Berisi tentang tata letak kedudukan modul praktikum. \\
\hline $\begin{array}{l}\text { Lembar Kerja } \\
\text { Praktikum ke-n, }\end{array}$ & $\begin{array}{l}\text { Kegiatan praktikum ini terdiri atas: (a) Tujuan; (b) Dasar } \\
\text { Teori; (c) Lembar Praktikum yang terdiri atas: alat dan } \\
\text { bahan, K3, langkah percobaan, hasil percobaan, } \\
\text { Analisis, Kesimpulan; (d) Latihan; (e) Kunci Jawaban; } \\
\text { (f) Daftar Pustaka; dan (g) Rubrik Penilaian. }\end{array}$ \\
\hline
\end{tabular}

Setiap lembar kerja praktikum memiliki tujuan sebagai berikut:(1) mahasiswa mampu mengetahui prinsip kerja dan karakteristik oscilator-n, (2)mahasiswa mampu merancang rangkaian oscilator-n secara teori dengan benar, (3)mahasiswa mampu merangkai dan menguji rangkaian oscilator-n secara praktik dengan menggunakan alat ukur, dan (4) mahasiswa mampu membuat analisa dan kesimpulan dari hasil praktikum oscilator-n.Adapun soal evaluasi disusun dengan mengacu pada tujuan pembelajaran tersebut.

Dalam pelaksanaan praktikum, mahasiswa akan dinilai dalam tiga ranah, yakni dilihat dari: (1) aspek kognitif dimana penilaian ini diambil dari skor yang didapat dari hasil menjawab soal evaluasi pada modul praktikum; (2) aspek psikomotorik yang didapat dari 
skorkebenaran hasil praktek, keselamatan kerja, prosedur kerja dan efektivitas waktu praktikum (skor tertinggi adalah empat dan terendah adalah satu); dan (3) aspek afektif yang didapat dari skor aktif dalam kegiatan praktikum, dapat bekerja sama dengan kelompok, tidak bergurau saat praktikum dan jujur dalam menyajikan data (skor tertinggi adalah empat dan terendah adalah satu). Selanjutnya untuk mengetaui nilai akhir keseluruhan aspek dapat dihitung oleh dosen pengampu mata kuliah yang bersangkutan, misalnya dengan porsi $50 \%$ untuk psikomotorik, 30\% untuk kognitif dan 20\% untuk afektif. Namun sebagai saran, agar aspek-aspek kemampuan yang dimiliki mahasiswa seimbang maka porsi penilian harus berimbang pula, yakni masing-masing 33,3\%.

Setelah dilakukan pembuatan trainer, langkah selanjutnya adalah pengujian masingmasing trainer untuk memastikan apakah trainer yang telah dikembangkan telah sesuai dengan perhitungan teori atau tidak. Penulis telah melakukan penurunan rumus dari masingmasing osilator yang telah dibahas dalam makalah lainnya [10]. Hasil pengujian fungsional ini ditunjukkan pada Tabel 9, Tabel 10, Tabel 11 dan Tabel 12.Berikut merupakan persamaan masing-masing osilator yang telah dikembangkan (keterangan: phi atau $\pi=3.14$ ), hasil perhitungan teori dibandingkan dengan data praktikum.

$$
\begin{array}{ll}
f=\frac{1}{2 \pi R C} & \text { [Wien bridge] } \\
f=1 /(2.1976 \mathrm{RC}) & \text { [Astable multivibrator] } \\
f=\frac{1}{2 \pi \sqrt{C L_{T}}} & \text { [Hartley] } \\
\text { Dengan } \mathrm{L}_{\mathrm{T}}=\mathrm{L} 1+\mathrm{L} 2 & \text { [Colpitts] } \\
f=\frac{1}{2 \pi \sqrt{L C_{T}}} & \\
\text { Dengan } \mathrm{C}_{\mathrm{T}}=\frac{\mathrm{C} 1 \mathrm{xC} 2}{\mathrm{C} 1+\mathrm{C} 2} &
\end{array}
$$

Tahap "validasi desain", Proses validasi dilakukan dengan cara memberikan angket kepada ahli (expert) mediayang dipilih karenakompetensinya atau track record pengalamannya dalam menilai produk pembelajarandan ahli materi sebagai narasumber. Dari validasi ini diperoleh dua jenis data yakni data kualitatif yang merupakan penilaian berupa kritik dan saran. Sedangkan data kuantitatif adalah angka validitas yang didapat dari perhitungan statistik dari angket. Produk yang divalidasi adalah: (1) Trainer, (2) Modul praktikum pegangan dosen, (3) Modul praktikum untuk pahasiswa, dan (4) Petunjuk penggunaan alat atau manual book).

Tahap "revisi desain", pada tahap ini dilakukan revisi berdasarkan data kuantitatif dan kualitatif dari ahli media dan ahli materi.Tahap selanjutnya adalah"uji coba kelompok kecil" yang dilakukan kepada mahasiswa program S1 Pendidikan Teknik Elektro JTE FT UM dengan syarat mereka sudah menempuh mata kuliahWorkshop Instrumentasi Industri. Jumlah mahasiswa uji coba adalah 5 orang. Tujuan dari validasi ini untuk mengetahui bagaimana respon mereka selaku peserta didik atas pemanfaatan produk hasil penelitian pengembangan ini. Instrumen yang digunakan adalah berupa angket yang isinya respon mahasiswa terhadap: 
(1) Trainer, (2) modul praktikum pegangan dosen, (3) modul praktikum untuk mahasiswa, dan (4) manual book.

Tahap "revisi produk",setelah proses uji coba kelompok kecil, maka didapatkan data kualitatif dan kuantitatif tentang respon mahasiswa. Pada tahap ini juga dilakukan konsultasi kepada dosen pengampu mata kuliahuntuk membantu mengarahkan dalam perbaikan produk apabila terdapat kekurangan dari produk penelitian pengembangan.

Tahap"uji lapangan"atau kelompok besar, produk penelitian pengembangantelah tervalidasi oleh para ahli danbeberapa mahasiswa pada kelompok kecil, selanjutnyaproduk siap untuk diuji-cobakan dalam kelompok besar yakni mahasiswa program S1 Pendidikan Teknik Elektro JTE FT UM, yang sudah menempuh Workshop Instrumentasi Industri (PTEL 660), berjumlah 34 orang.Kemudian adalahrevisi akhir produk berdasarkan data-data dari validator dan uji coba kelompok besar.Tahap "produk akhir", setelah Trainer, modul praktikum pegangan dosen, modul praktikum untuk mahasiswa, dan manual booktelah sesuai standar(valid)maka kegiatan penelitian pengembangan ini telah selesai, artinya produk telah siap digunakan daam pembelajaran.

Data-data yang diperoleh dari skor angket kemudian di analisis dengan menggunakan teknik data persentase menurut Akbar[11]. Rumus untuk mengolah data ahli materi/media mengacu pada Persamaan (5), sedangkan untuk responden pengguna (mahasiswa) merujuk pada Persamaan (6),

$$
\begin{aligned}
& \mathrm{Va}=\frac{\mathrm{TSe}}{\mathrm{TSh}} \times 100 \% \\
& \mathrm{Vp}=\frac{\mathrm{TSe}}{\mathrm{TSh}} \times 100 \%
\end{aligned}
$$

Keterangan:

Va: Validitas dari ahli, Vp: Validitas dari pengguna, 100\%: Kontanta, TSh: Total skor maksimal yang diharapkan, Tse: Total skor empiris (hasil validasi dari validator)

Tabel 3. Pedoman penentuan kelayakan media

\begin{tabular}{ccl}
\hline No & Kriteria Validitas & \multicolumn{1}{c}{ Tingkat Validitas } \\
\hline 1 & $81,26 \%-100,00 \%$ & $\begin{array}{l}\text { Sangat Valid, atau dapat digunakan tanpa } \\
\text { revisi }\end{array}$ \\
\hline 2 & $62,51 \%-81,25 \%$ & $\begin{array}{l}\text { Cukup Valid, atau dapat digunakan namun } \\
\text { perlu revisi kecil }\end{array}$ \\
\hline 3 & $43,76-62,50 \%$ & $\begin{array}{l}\text { Kurang valid, disarankan tidak dipergunakan } \\
\text { karena perlu revisi besar }\end{array}$ \\
\hline 4 & $25,00 \%-43,75 \%$ & Tidak valid, atau tidak boleh dipergunakan \\
\hline
\end{tabular}

Kriteria validitas dilakukan dengan proses sebagai berikut: Jumlah item validasi untuk ahli materi adalah 24 item, sehingga skor maksimal apabila validator memberi skor 4 semua untuk seluruh item adalah $24 \times 4=96$. Skor terendahnya adalah $24 \times 1=24$, selanjutnya dimasukkan ke persamaan 1 sehingga $(24 / 96) \times 100 \%=25 \%$ untuk persentase minimal, dan $100 \%$ untuk persentase maksimal. Selisih skor maksimal dan minimal adalah $75 \%$. Menggunakan konversi skala Likert dengan empat tingkatan, maka kita membuat kriteria 
validitas menjadi empat kelas interval. Besar interval antar kelas diperoleh dengan membagi selisih skor maksimal dan skor minimal menjadi empat, berarti $18,75 \%$.

Peneliti dapat menentukan sendiri kriteria validitas disesuaikan dengan banyaknya item dalam instrumen dan cara menilai membuat skornya. Berdasarkan perhitungan tersebut, maka ditetapkan kriteria presentase dengan pedoman interprestasi yang digunakan ditunjukkan pada Tabel 3 yakni merupakan pedoman dalam pengambilan keputusan dari analisis data dan menentukan kesimpulan dari apa yang telah tercapai. Perangkat pembelajaran yang terdiri atas trainer, modul ajar cetak dan manual book dapat dipergunakan dalam proses belajar mengajar apabila sudah mencapai mencapai kriteria cukup validdan 81,26 \% - 100,00\%.

\section{A. Waktu dan Tempat Pelaksanaan}

Kegiatan peneltian dilaksanakan dari awal bulan Februari sampai dengan bulan Juni dan dilakukan di:

1. Laboratorium elektronika (Lab. Elka) dan Laboratorium elektronika digital (Lab. Eldig) di JTE FT UM sebagai tempat soldering, instalasi dan pengkabelan (wiring), dan pengujian menggunakan alat ukur.

2. Bengkel mekanik gedung G4 JTE FT UM sebagai tempat pengerjaan box daritrainerosilator.

3. Kampus ITB sebagai tempat diseminasi produk penelitian pengembangan.

\section{B. Desain Penelitian Pengembangan}

Terdapat dua jenis validasi yang digunakan, yakni validasi deskriptif kualitatif dan kuantitatif dengan persentase skor validitas. Hal ini dilakukan untuk menjelaskan kelayakan dari produk yang dihasilkan. Pelaksanaan uji kelayakan dilakukan dengan menyerahkan angket kepada ahli materi dan ahli media untuk melakukan penilaian dan memutuskan layak atau tidaknya trainer yang telah dibuat. Uji coba pemakaian dilakukan setelah ada keputusan dari ahli media dan ahli materi, jika keduanya memutuskan layak maka uji coba pemakaian dilakukan melalui dua tahapan yaitu uji coba kelompok kecil dan uji coba kelompok besar.

Subjek validasi dalam penelitian ini terpilih dua expert, yaknisatu ahli media dan satu dosen pengampu mata kuliah Program Studi Pendidikan Teknik Elektro JTE FT UM sebagai ahli materi.Subjek pada uji coba ini merupakan sampel acak yang diambil dari seluruh mahasiswa JTE FT UM padaProdi S1 Pendidikan Teknik Elektro yang telah menempuh mata kuliah Workshop Instrumentasi Industri sebagai populasi.

\section{Jenis Data}

Terdapat dua jenis data yang didapatkan dalam penelitian ini, yakni data kuantitatif yang merupakan persentase dan nilai rata-rata dari angket, data tersebutdidapatkan dari penilaian validitas produk penelitian pengembangan dari validator berupa angka 4,3,2, dan 1 . Sementara data kualitatif merupakan tanggapan/kritik/saran yang diberikan oleh validator berkaitan denganproduk hasil penelitian pengembangan tersebut.

\section{Instrumen Pengumpulan Data}

Instrumen yang digunakan untuk mengumpulkan data yaitu kuisioner/angket tertutup, yakni kuisioner yang telah disediakan pilihan jawabanya sehingga responden tinggal memilih jawaban sesuai hanya dengan memberi tanda cek pada kolom-kolom jawaban yang telah disediakan (Check list).

Arikunto [12]menyatakan bahwa sebelum menyusun angket ada beberapa prosedur 
yang harus dilalui yaitu:

a. Merumuskan tujuan yang akan dicapai dengan angket. Rumusan dari tujuan yang akan dicapai dalam angket ini adalah untuk mengetahui kelayakan trainerosilator, modul praktikum dan manual book.

b. Mengidentifikasi variabel yang akan dijadikan sasaran angket. Variabel tersebut adalah tingkat kelayakan atau validitas media pembelajaran.

c. Menjabarkan setiap variabel menjadi subvariabel yang lebih spesifik dan tunggal (indikator atau subindikator).

d. Menentukan jenis data yang akan dikumpulkan, sekaligus untuk menentukan teknik analisisnya yang dalam hal ini adalah data kuantitatif dan kualitatif.

Kuisioner yang telah disusundiberikan kepada validator yang telah dipilih sebelumnya dan juga kepada mahasiswa sebagai subjek uji coba. 


\section{Hasil dan Pembahasan}

Produk yang diahasilkan

Produk yang dihasilkan dalam penelitian pengembangan ini adalah trainerosilatoryang dilengkapi dengan modul praktikum untuk mahasiswa, modul praktikum pegangan dosen dan manual bookuntuk menunjang pembelajaran pada mata kuliah Workshop InstrumentasiIndustri di JTE FT UM dengan subbahasan pembangkit sinyal.

Terdapat tiga jenis trainer yang dikembangkan, yakni jenis osilator feedback RC, feedback LC dan Relaksasi. Untuk jenis osilator RC yakni: (a) Phase shift RC; (b) Wien bridge [13]. Untuk osilator LC [14] yakni: (c) Hartley; (d) Colpitts. Sedangkan untuk osilator Relaksasi yakni: (e) Astable multivibrator [15].Sinyal output pada trainer osilator ini hanya dapat dilihat menggunakan alat ukur oscilloscope dan frequency counter.

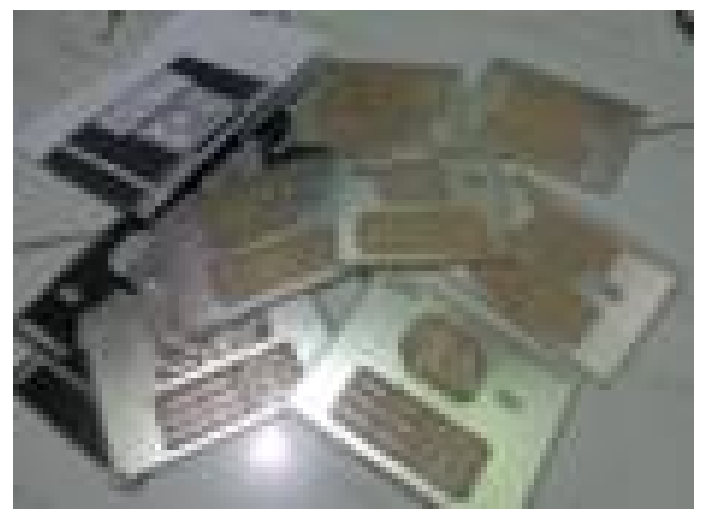

(a)

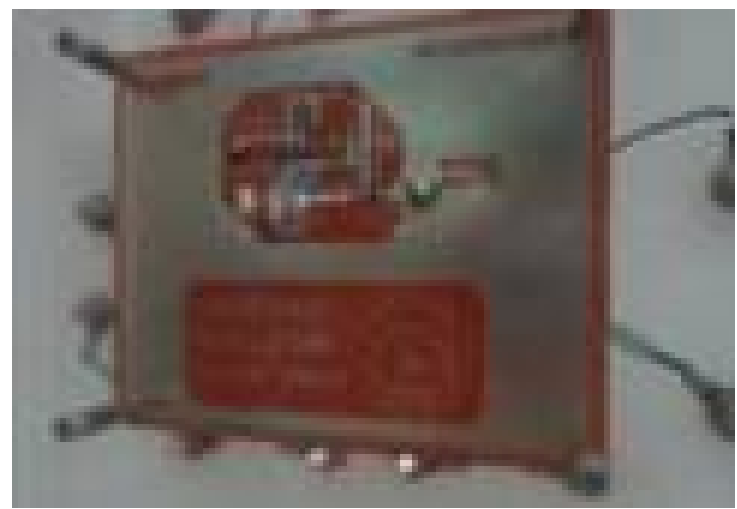

(b)

Gambar 3 (a) Hasil printing PCB dari trainer osilator; (b) PCB yang telah dikemas terintegrasi dengan casing dari trainer osilator

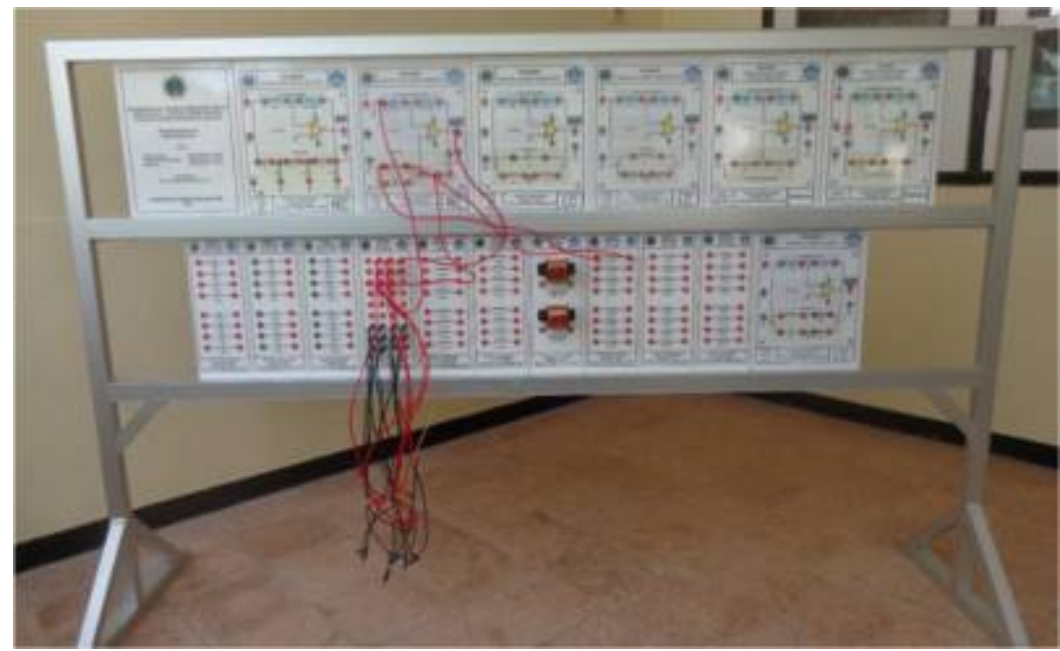

Gambar 4. Trainer osilator yang telah dikembangkan

Layout PCB dibuat menggunakan bantuan perangkat lunak Eagle versi free dan hasil tercetaknya pada single layer ditunjukkan pada Gambar 3(a) sedangkan hasil akhir (setelah proses soldering dan wiring) ditunjukkan pada Gambar 3(b). Box untuk trainer osilator 
terbuat dari dua bahan Acrylic, pada bagian depan adalah milk acrylic dengan tebal $5 \mathrm{~mm}$ dan glass acrylic pada bagian belakang dengan tebal $4 \mathrm{~mm}$. Gambar 4 merupakan hasil penelitian pengembangan dan spesifikasinya ditunjukkan pada Tabel 4.Total terdapat enam belas buah modul hardware yang terdiri atas lima buah trainer, tiga buah modul resistor, tiga buah modul capacitor, tiga buah modul inductor dan satu buah tempat jumper.

Penulis menggunakan IC general Op-Amp yakni LM741 dengan alasan karena harga IC terjangkau dan mudah dicari dipasaran elektronik Indonesia, terutama didaerah Malang, Jawa Timur. Sehingga apabila terjadi trouble pada IC dapat diselesaikann dengan segera. Resistor dipilih dari jenis metalfilm karena memiliki toleransi yang lebih kecil dibandingkan jenis carbon. Sedangkan capacitordipilih dari jenis Mylar. Untuk lebih presisi dapat dipergunakan dari jenis Tantalum.

Modul praktikum untuk mahasiswa berisi kegiatan belajar yang memberikan informasi kepada mereka tentang karakteristik dan prisip kerja osilator serta mempraktikannya dalam lembar kerja yang telah disediakan. Dengan kegiatan belajar tersebut diharapkan mahasiswa memiliki kompetensi dalam rangka penguasaan kompetensi sistem instrumentasi industri, sertamemiliki kemampuan yangmemadai untuk dapat mengaplikasikan rangkiaan osilator pada suatu sistem tertentu. Manual book berisi tentang spesifikasi trainerosilator, kesehatan dan K3, fungsi masing-masing blok, langkah-langkah dalam mengoperasikan trainerdengan baik dan benar. Tujuannya adalah untuk mempermudah kegiatan belajar agar dalam proses praktikum dapat berjalan maksimal.

Tabel 4.Spesifikasi produk trainer yang telah dikembangkan

\begin{tabular}{|c|c|}
\hline Parameter & Keterangan \\
\hline Kuantitas produk & $\begin{array}{l}\text { - } \text { Osilator Phase shift RC } \\
\text { - Osilator Wien bridge } \\
\text { - Osilator Hartley } \\
\text { - } \text { Osilator Colpitts } \\
\text { - } \text { Astable multivibrator } \\
\text { - Modul R } 1 \mathrm{k} \Omega \& 10 \mathrm{k} \Omega \\
\text { - Modul R } 2 \mathrm{k} \Omega \& 20 \mathrm{k} \Omega \\
\text { - Modul R } 3 \mathrm{k} \Omega \& 30 \mathrm{k} \Omega \\
\text { - Modul C } 10 \mathrm{nF} \& 100 \mathrm{nF} \\
\text { - Modul C } 1 \mu \mathrm{F} \mathrm{\&} 10 \mu \mathrm{F} \\
\text { - Modul C } 100 \mu \mathrm{F} \& 1000 \mu \mathrm{F} \\
\text { - Modul L } 100 \mu \mathrm{H} \\
\text { - Modul L } 50 \mu \mathrm{H} \& 200 \mu \mathrm{H} \\
\text { - Modul L } 1000 \mathrm{Wdg} \& 500 \mathrm{Wdg} \\
\text { - Jumper trainer osilator } \\
\text { Masing-masing modul disediakan sebanyak } 1 \text { buah, } \\
\text { sehingga jumlah total adalah } 16 \text { buah modul }\end{array}$ \\
\hline Integrated Circuit (IC) & IC OP-AMP 741 \\
\hline $\begin{array}{l}\text { Tegangan untuk VCC \& } \\
\text { VEE }\end{array}$ & $\begin{array}{l}\text { Maksimum }+12 \text { Volt } \\
\text { Maksimum - } 12 \text { Volt }\end{array}$ \\
\hline $\begin{array}{l}\text { Warna nyala /ukuran LED } \\
\text { indikator }\end{array}$ & merah/ $3 \mathrm{~mm}$ \\
\hline
\end{tabular}




\begin{tabular}{|c|c|}
\hline $\begin{array}{l}\text { Warna pindari banana } \\
\text { plug }\end{array}$ & $\begin{array}{l}\text { - VCC: Merah } \\
\text { - VEE: Hitam } \\
\text { - GND: Hijau }\end{array}$ \\
\hline Body & Full acrylic \\
\hline Stiker & Vynil susu + Glossy \\
\hline $\begin{array}{l}\text { Printed Circuit Board } \\
\text { (PCB) }\end{array}$ & PCB Fiber lapis Silver \\
\hline Rentang frekuensi osilator & 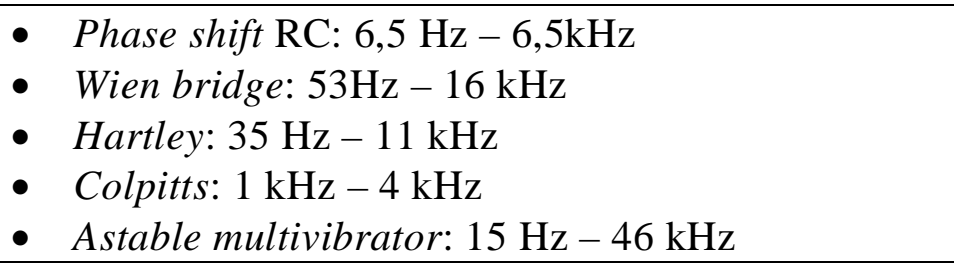 \\
\hline Spesifikasi resistor & Resistor tetap /metalfilm/0,5Watt \\
\hline Spesifikasi kapasitor & $\begin{array}{ll}- & \text { Kapasitor mylar } \\
\text { - } & \text { Kapasitor electrolit, tegangan maksimum: }+25 \mathrm{~V}_{\mathrm{DC}}\end{array}$ \\
\hline
\end{tabular}
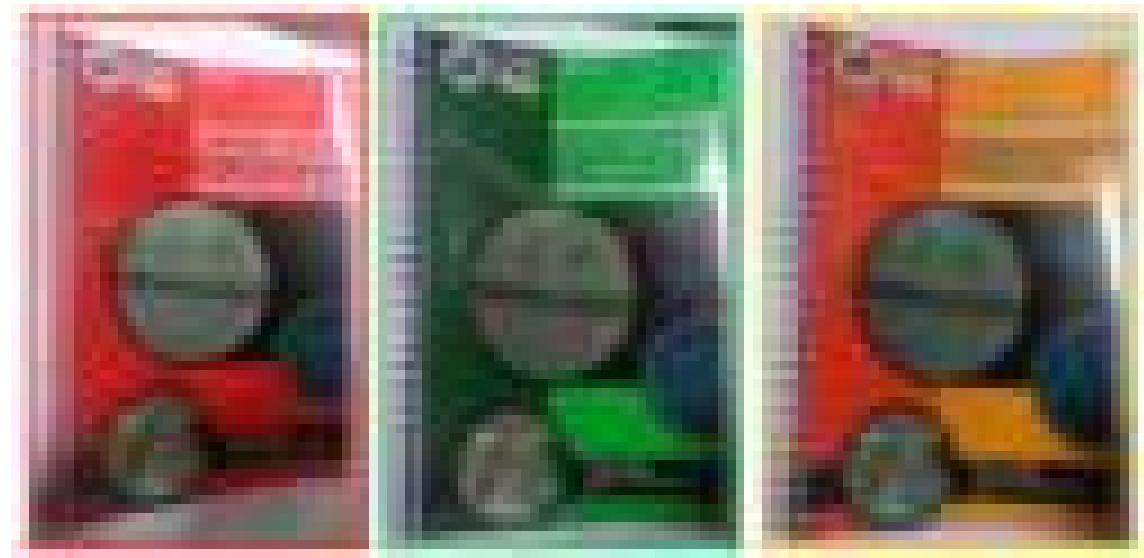

Gambar 5 Produk buku tercetak: manual book (kiri), modul praktikum untuk mahasiswa (tengah) dan modul praktikum pegangan dosen (kanan)

Pengoperasian Produk

Langkah pertama yang dilakukan peserta didik dalam melaksanakan kegiatan praktikum adalah menyiapkan semua alat dan bahan praktikumtermasuk alat ukur, modul praktikum,dantelah memahami petunjuk praktik pada lembar jobsheet dan juga membacamanual book secara seksama. Selanjutnya, mahasiswa melakukan aktivitas plug dan play dari modul RLC ke trainer -ilustrasi ditunjukkan pada Gambar 6(a)-kemudian penyambungan ke alat ukur dan penyambungan ke power suplai. Praktikan melihat hasil sinyaloutputdari osilator seperti ditunjukkan oleh alat ukur pada osciloscope(Gambar 6(b)) dan frequency counter, kemudian memasukkan kedalam tabel percobaan.

Tabel 5 merupakan kebutuhan modul RLC pada masing-masing praktikum. Di JTE FT UM, jumlah oscilloscope digital sangat terbatas. Atas dasar itulah oscilloscope analog dipergunakan sebagai referensi praktikum (hanya untuk melihat bentuk sinyal), untuk melihat angka yang lebih detail dipergunakan alat ukur frequency counter.

Pada proses berikutnya, peserta didik mengganti komponen resistor, capacitor atau 
inductor sesuai tabel percobaan, sehingga tidak diperbolehkan mengganti $\mathrm{R} / \mathrm{L} / \mathrm{C}$ sesuai keinginan, karena tidak semua kombinasi menghasilkan osilasi seperti pada praktikum osilator Hartley dan Colpitts [14]. Setelah mendapatkan data, praktikan harus melakukan analisishasil percobaan dan terakhir diharuskan untuk menarik kesimpulan dari pelaksanaan praktikum yang telah dilakukan. Selain itu, praktikan diwajibkan untuk mengerjakan soal-soal evaluasi yang telah tersedia pada modul praktikum.

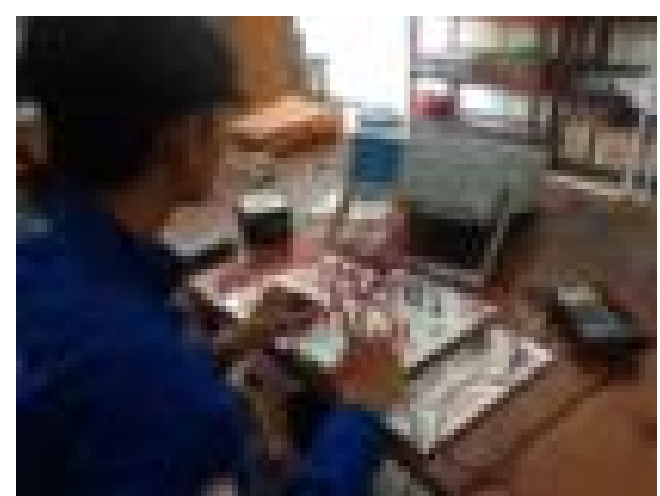

(a)

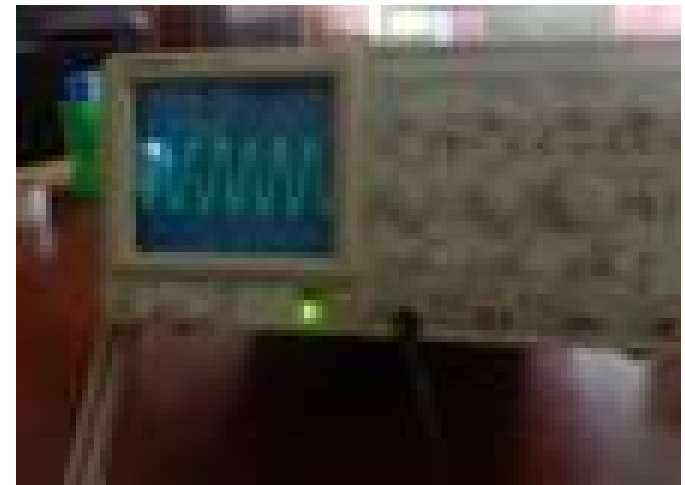

(b)

Gambar 6. (a) Ilustrasi pengoperasian produk dengan cara plug and play (b) hasil output sinyal osilator yang ditunjukkan oleh alat ukur oscilloscope

\section{Validasi Produk}

Merujuk pada metode penelitian pengembangan, produk diujikan kepada tiga subyek coba, diantaranya yaitu ahli media, ahli materi, dan praktikan (mahasiswa), data kuantitatif yang dihimpun diperoleh dari isian instrument angket. Hasil validasi per-produk ditunjukkan pada Tabel 6, Tabel 7 dan Tabel 8.

Tabel 5.Kebutuhan media praktikum

\begin{tabular}{|l|l|l|l|l|l|l|l|l|l|l|l|l|l|l|}
\hline $\begin{array}{l}\text { Praktikum } \\
\text { Osilator }\end{array}$ & $\mathrm{C}$ & $\mathrm{C}$ & $\mathrm{C}$ & $\mathrm{C}$ & $\mathrm{C}$ & $\mathrm{C}$ & $\mathrm{R}$ & $\mathrm{R}$ & $\mathrm{R}$ & $\mathrm{R}$ & $\mathrm{R}$ & $\mathrm{R}$ & $\mathrm{L}$ & $\mathrm{L}$ \\
\hline $\begin{array}{l}\text { Phase shift } \\
\mathrm{RC}\end{array}$ & & & & & & & & & & & & & & \\
\hline Wien bridge & & & & & & & & & & & & & & \\
\hline Hartley & & & & & & & & & & & & & & \\
\hline Colpitts & & & & & & & & & & & & & & \\
\hline $\begin{array}{l}\text { Astable } \\
\text { multivibrator }\end{array}$ & & & & & & & & & & & & & & \\
\hline
\end{tabular}

Tabel 6.Data hasil ahli media untuk penilaian trainer

\begin{tabular}{|l|l|l|l|}
\hline No & Pernyataan & $\begin{array}{l}\text { Persentase } \\
\text { penilaian Ahli } \\
\text { Media }\end{array}$ & Kriteria \\
\hline 1 & Trainer berfungsi dengan baik & $100 \%$ & SV \\
\hline 2 & Trainer efektif digunakan dalam pembelajaran & $75 \%$ & V \\
\hline
\end{tabular}




\begin{tabular}{|l|l|l|l|}
\hline 3 & $\begin{array}{l}\text { Trainer dilengkapi dengan lampu indikator VCC } \\
\text { dan VEE dan berfungsi dengan baik }\end{array}$ & $100 \%$ & $\mathrm{SV}$ \\
\hline 4 & Kabel penghubung berfungsi dengan baik & $100 \%$ & $\mathrm{SV}$ \\
\hline 5 & $\begin{array}{l}\text { Trainer mudah digunakan dan sederhana dalam } \\
\text { pengoperasiannya }\end{array}$ & $75 \%$ & $\mathrm{~V}$ \\
\hline 6 & $\begin{array}{l}\text { Ketepatan komposisi (gambar rangkaian, sumber } \\
\text { tegangan, alat ukur, komponen, lampu indikator, } \\
\text { keterangan) }\end{array}$ & $75 \%$ & $\mathrm{~V}$ \\
\hline 7 & $\begin{array}{l}\text { Keterangan komponen dan banana port pada } \\
\text { trainer ditampilkan dengan jelas }\end{array}$ & $100 \%$ & $\mathrm{SV}$ \\
\hline 8 & $\begin{array}{l}\text { Keterangan sumber tegangan dan output } \\
\text { ditampilkan secara jelas }\end{array}$ & $100 \%$ & $\mathrm{SV}$ \\
\hline 9 & Warna banana plug pada trainer sudah sesuai & $100 \%$ & $\mathrm{SV}$ \\
\hline 10 & $\begin{array}{l}\text { Gambar rangkaian pada trainer memperjelas } \\
\text { pemahaman penggunaan }\end{array}$ & $100 \%$ & $\mathrm{SV}$ \\
\hline 11 & Tulisan pada trainer jelas terbaca & $100 \%$ & $\mathrm{~V}$ \\
\hline 12 & Pemilihan bahan pada trainer berkualitas & $100 \%$ & $\mathrm{SV}$ \\
\hline 13 & $\begin{array}{l}\text { Frekuensi output dari trainer telah sesuai dengan } \\
\text { teori dasar perhitungan frekuensi pada masing- } \\
\text { masing oscilator }\end{array}$ & $100 \%$ & $\mathrm{SV}$ \\
\hline 14 & $\begin{array}{l}\text { Ukuran trainer tepat (tidak terlalu kecil dan tidak } \\
\text { terlalu besar) }\end{array}$ & $100 \%$ & $\mathrm{SV}$ \\
\hline 15 & Desain trainer menarik secara keseluruhan & $75 \%$ & $\mathrm{~V}$ \\
\hline Total & $\mathbf{9 3 , 3 3 \%}$ & $\mathrm{SV}$ \\
\hline
\end{tabular}

Keterangan $=\mathbf{S V}:$ sangat valid, $\mathbf{V}:$ valid

Tabel 7.data hasil ahli media dan ahli materi untuk penilaian manual book

\begin{tabular}{|l|l|c|c|}
\hline No & Pernyataan & $\begin{array}{l}\text { Persentase } \\
\text { penilaian } \\
\text { ahli media }\end{array}$ & $\begin{array}{l}\text { Persentase } \\
\text { penilaian } \\
\text { ahli materi }\end{array}$ \\
\hline 1 & $\begin{array}{l}\text { Menyebutkan keterangan masing-masing pin } \\
\text { banana pada trainer }\end{array}$ & $75 \%$ & $100 \%$ \\
\hline 2 & $\begin{array}{l}\text { Gambar dan warna pada buku petunjuk penggunaan } \\
\text { jelas dan menarik }\end{array}$ & $100 \%$ & $100 \%$ \\
\hline 3 & $\begin{array}{l}\text { Bahasa dalam buku petunjuk penggunaan trainer } \\
\text { jelas sehingga mudah dimengerti }\end{array}$ & $100 \%$ & $75 \%$ \\
\hline 4 & $\begin{array}{l}\text { Buku petunjuk penggunaan trainer disusun secara } \\
\text { sistematis }\end{array}$ & $100 \%$ & - \\
\hline 5 & $\begin{array}{l}\text { Daftar isi ditampilkan secara jelas } \\
\text { Muku petunjuk penggunaan trainer mudah untuk } \\
\text { dipahami }\end{array}$ & - & $100 \%$ \\
\hline \multicolumn{2}{|c|}{ Total } & $\mathbf{9 0 \%}$ & $\mathbf{9 3 , 7 5}$ \\
\hline
\end{tabular}


Tabel 8.Data hasil ahli media untuk penilaian modul pegangan dosen dan modul praktikum mahasiswa

\begin{tabular}{|c|c|c|c|}
\hline No & Pernyataan & $\begin{array}{l}\text { Persentase } \\
\text { penilaian } \\
\text { ahli media }\end{array}$ & $\begin{array}{l}\text { Persentase } \\
\text { penilaian } \\
\text { ahli materi }\end{array}$ \\
\hline 1 & Tujuan sesuai dengan silabus pembelajaran & $100 \%$ & $100 \%$ \\
\hline 2 & $\begin{array}{l}\text { Kesesuaian materi dalam jobsheet dengan tujuan } \\
\text { pembelajaran workshop instrumentasi industri }\end{array}$ & $100 \%$ & - \\
\hline 3 & Materi prasyarat dinyatakan dengan jelas & $100 \%$ & - \\
\hline 4 & Peta kedudukan modul dinyatakan dengan jelas & $100 \%$ & - \\
\hline 5 & Langkah-langkah K3 dijelaskan dengan jelas & $100 \%$ & - \\
\hline 6 & Ketepatan judul bab dengan isi materi & $100 \%$ & - \\
\hline 7 & Uraian materi mudah dipahami & $75 \%$ & - \\
\hline 8 & Materi pada modul ini disusun secara sistematis & $100 \%$ & $100 \%$ \\
\hline 9 & $\begin{array}{l}\text { Materi pada jobsheet sesuai dengan tingkat pemahaman } \\
\text { mahasiswa }\end{array}$ & $100 \%$ & - \\
\hline 10 & Keterangan alat dan bahan disebutkan dengan jelas & $100 \%$ & $75 \%$ \\
\hline 11 & $\begin{array}{l}\text { Langkah percobaan ditampilkan secara sistematis dan } \\
\text { memperjelas praktikum }\end{array}$ & $100 \%$ & $100 \%$ \\
\hline 12 & Paragraf disusun dengan baik & $100 \%$ & $100 \%$ \\
\hline 13 & Gambar rangkaian pada modul sesuai dengan isi materi & $100 \%$ & $100 \%$ \\
\hline 14 & Gambar dan warna menambah ketertarikan mahasiswa & $100 \%$ & - \\
\hline 15 & $\begin{array}{l}\text { Dengan modul yang dikembangkan ini pembelajaran } \\
\text { lebih interaktif }\end{array}$ & $75 \%$ & - \\
\hline 16 & Rubrik penilaian dinyatakan dengan jelas & $100 \%$ & $100 \%$ \\
\hline 17 & Bahasa dalam modul komunikatif & $75 \%$ & $100 \%$ \\
\hline 18 & Modul menarik secara keseluruhan & $100 \%$ & - \\
\hline 19 & Modul praktikum oscilator mudah digunakan & - & $100 \%$ \\
\hline 20 & $\begin{array}{l}\text { Modul praktikum oscilator dapat digunakan untuk belajar } \\
\text { mandiri }\end{array}$ & - & $100 \%$ \\
\hline 21 & $\begin{array}{l}\text { Modul praktikum oscilator sesuai tingkat pemahaman } \\
\text { mahasiswa }\end{array}$ & - & $100 \%$ \\
\hline 22 & $\begin{array}{l}\text { Petunjuk penggunaan modul praktikum sudah } \\
\text { ditampilkan }\end{array}$ & - & $100 \%$ \\
\hline 23 & Daftar isi sudah tersusun dengan baik. & - & $100 \%$ \\
\hline 24 & Dasar teori sudah ditampilkan & - & $100 \%$ \\
\hline 25 & Materi prasyarat dinyatakan dengan jelas & - & $100 \%$ \\
\hline 26 & Peta kedudukan modul dinyatakan dengan jelas & - & $100 \%$ \\
\hline 27 & K3 ditampilkan dengan jelas & - & $100 \%$ \\
\hline 28 & Ketepatan judul bab dengan isi materi & - & $100 \%$ \\
\hline 29 & Soal latihan ditampilkan secara jelas & - & $100 \%$ \\
\hline 30 & Soal latihan sesuai dengan tujuan pembelajaran & - & $100 \%$ \\
\hline 31 & Daftar pustaka ditampilkan jelas & - & $100 \%$ \\
\hline
\end{tabular}




\begin{tabular}{|l|l|l|l|}
\hline 32 & Sesuai dengan kaidah penulisan PPKI UM & - & $100 \%$ \\
\hline Total & $\mathbf{9 5 , 8 3 \%}$ & $\mathbf{9 8 , 8 6 \%}$ \\
\hline
\end{tabular}

Sedangkan grafik validitas media per-responden ditunjukkan pada Gambar 8 dengan skala grafik dimulai dari $50,00 \%$ sampai $100,00 \%$. Secara rinci dijabarkan berikut:

\section{Validasi Ahli Media}

Hasil uji coba dilakukan kepada ahli media sebanyakdua kali dengan menggunakanintrumen angket 37 item pertanyaan. Berdasarkan hasil hitung didapatkan persentase skor ahli media: (1)aspek efektivitas 91,67\%; (2)aspek kemudahan 93,75\%; (3)aspek kesesuaian 100\%; (4)aspek kelengkapan 100\% ; (5)aspek interaktivitas 90,38\%.

\section{Validasi Ahli Materi}

Hasil uji coba dilakukan kepada ahli materi sebanyakdua kali dengan menggunakan intrumen angket 27 item pertanyaan. Berdasarkan hasil hitung didapatkan persentase skor ahli materi: (1) aspek kesesuaian100\% ; (2)aspek kelengkapan95,83\%; (3)aspek kemudahan100\%; (4) aspek kejelasan 95\%.

3. Uji Coba Kelompok Kecil dan Besar

Subyek uji coba kelompok kecil dan besar ini adalah mahasiswa S1 Pendidikan Teknik Elektro JTE FT UM yang baru saja menempuh mata kuliah Workshop Instrumentasi Industri dengan menggunakan intrumen angket 35 item pertanyaan. Sebanyak 5 (Lima) orang dikelompok kecil dan 34 (tiga puluh empat) orang dikelompok besar.

Berdasarkan hasil hitung didapatkan persentase skor uji coba kelompok kecil:(1) aspek kemudahan 95\%; (2) aspek kejelasan 95,67\%; (3) aspek kesesuaian 91,67\%; (4) aspek tampilan 92,50\%; (5) aspek kemenarikan 92,50\%. Kemudian Berdasarkan hasil hitung didapatkan persentase skor uji coba kelompok besar: (1) aspek kemudahan 94,85\%; (2) aspek kejelasan 93,77\%; (3) aspek kesesuaian 93,38\%; (4) aspek tampilan 93,38\%; (5) aspek kemenarikan $93,01 \%$.

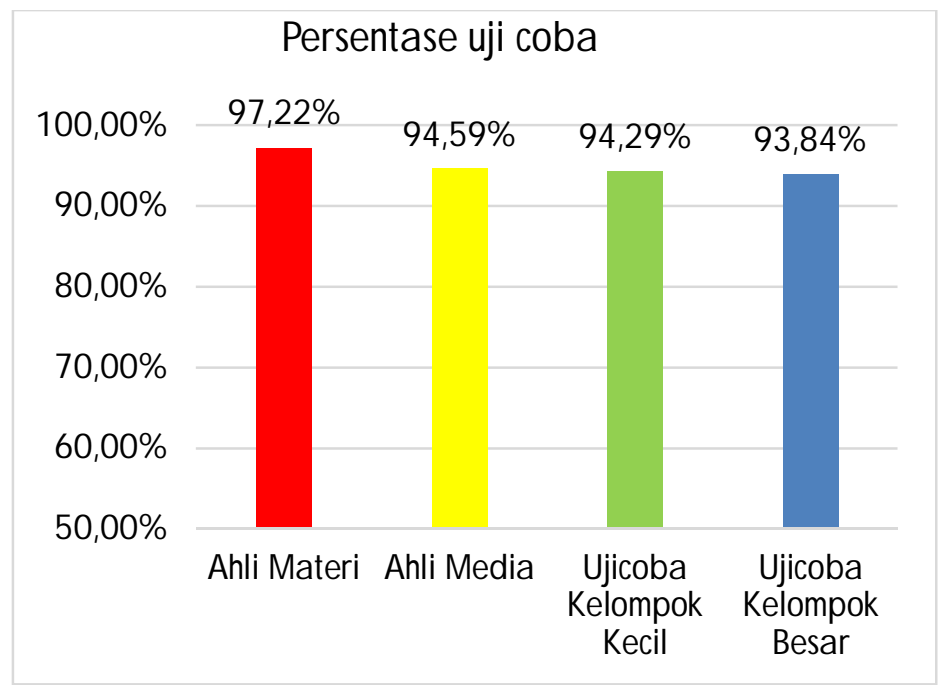

Gambar 8. Presentase rata-rata validitas produk penelitian pengembangan: 94,59\% untuk ahli media 97,22\% untuk ahli materi dan 94,29\% untuk uji coba kelompok kecil dan 93,84\% untuk uji coba kelompok besar. 
Merujuk kriteria validitas pada Tabel 3, maka keseluruhan data hasil tersebut dinyatakan sangat valid,yakni masuk dari rentang 85,01\% - 100\% sehingga media pembelajaran (mencakup trainer dan perangkat pendukung) telah dapat dipergunakan dalam pelaksanaan praktikum osilator pada mata kuliah Workshop Instrumentasi Industri di JTE FT UM.

\section{Kesimpulan}

Penelitian pengembangan ini dilatarbelakangi oleh ketidakseterdiaan media pembelajaran pembangkit sinyal (osilator) pada salah satu mata kuliah praktikum yang diajarkan pada mahasiswa JTE FT UM, yakni mata kuliah Workshop Instrumentasi Industri. Pengembangan trainer osilator ini merupakan salah satu solusi untuk menunjang pembelajaran praktikum yang bertujuan utnukmembangun sebuah pola pikir dan kerangka pikir dari mahasiswa dalam mempelajari materi pada mata kuliahyang bersangkutan.

Trainer osilator yang telah dikembangkan adalah: (a) Phase shift RC; (b) Wien bridge; (c) Hartley; (d) Colpitts; dan (e) Astable multivibrator. Perangkat trainer dilengkapi dengan modul praktikum pegangan dosen, modul untuk mahasiswa dan manual book. Ketiga produk penelitian tersebut telah tervalidasi dan mendapat respon positif dari mahasiswa praktikan (sangat valid).

\section{Daftar Pustaka}

S. Fuada, "Perancangan sistem control pada prototip pengering kerupuk berbasis IC digital menggunakan software Proteus 7.0," J. Setrum, Vol. 6(2), pp. 88-96, Juni 2017.

S. Fuada and F.T. Aquari, "Square wave generator circuit analysis using Matlab approach," Int. J. of Engineering Sciences \& Research Technology(IJESRT), Vol. 2(2), pp. 371-382, February 2013.

S. Fuada and A.H. Salman, "Virtual labs of analog oscillator," Int. J. of Online Engineering (IJOE), Vol. 12(8), pp. 31-32, 2016. DOI: http://dx.doi.org/10.3991/ijoe.v12i08.5911

S. Fuada and A.W. Wibowo, "Desain dan implementasi virtual laboratory materi osilator analog berbasis IC OP-AMP," J. Elkomika, Vol. 4(2), pp. 134-147, Desember 2016.

A.W. Wibowo and S. Fuada, "Media pembelajaran analog oscillator virtual lablatory," J. Telematika, Vol. 13(1), pp. 23-30, January 2016.

Silabus Workshop Instrumentasi Industri (PTEL 660). Katalog Jurusan Teknik Elektro Fakultas Teknik Universitas Negeri Malang, pp 120.

Suryani, "Pemodelan \& Simulasi," Yogyakarta: Graha Ilmu, 2006.

Daryanto, "Menyusun Modul: Bahan ajar untuk persiapan guru dalam mengajar," Yogyakarta: Gava Media, 2006.

Sugiyono, "Metode Penelitian Pendidikan Kuantitatif, Kualitatif, dan R\&D," Bandung: Alfabeta, 2011.

S. Fuada, "Pengujian Validitas Alat Peraga Pembangkit Sinyal (Oscillator) untuk Pembelajaran Workshop Instrumentasi Industri," Proc. of Seminar Nasional Pendidikan (SEMNASDIK), pp. 854-861, November 2015.

S. Akbar, "Instrumen Perangkat Pembelajaran," Bandung: PT Remaja Rosdakarya, 2011.

S. Arikunto, "Prosedur Penelitian Suatu Pendekatan Praktik (Edisi Revisi 2010)". Jakarta: PT Rineka Cipta, 2010.

S. Fuada, "Pengujian Trainer Oscilator Wien Bridge dengan Menggunakan Osciloskop dan Frekuensi Counter". Proc. of Seminar Nasional Teknologi Informasi dan Aplikasinya (SENTIA). Vol. 6, pp. A32-A36, Juni 2014. 
S. Fuada, H. Elmunsyah and Suwasono, "Design and Fabrication of LC-Oscillator Tool Kits Based Op-Amp for Engineering Education Purpose," Indonesian J. of Electrical Engineering and Computer Science, Vol. 1(1), pp. 88-100, January 2016. DOI: http://dx.doi.org/10.11591/ijeecs.v1.i1.pp88-100

S. Fuada, "Pembuatan Trainer Board Astable Multivibrator (AM) Sebagai Media Pembelajaran,”Jurnal Nasional Teknik Elektro (JNTE), Vol. 5(2), pp. 244-251, Juli 2016. 